\title{
A New Framework for Learning Approaches toward Social Evolution of Organizations
}

\author{
Mohammad Ali Kashefi $^{1}$ and Mohammad Ebrahim Sanjaghi ${ }^{2}$
}

\begin{abstract}
This paper addresses a gap in the literature concerning suitability of organizational learning approaches in facing social responsibility challenges, and proposes a developed framework that could proactively bridge this gap. A new framework is designed in order to gain insight on the relationships between the typical organizational learning approaches- which have been discussed extensively so far in the literature- and the brandnew concept of civil learning come out of Corporate Social Responsibility (CSR) studies in very recent years. Comparative analysis is employed to identify well-adjusted organizational learning approaches toward social evolution of organizations. Indeed we are looking to propose a specific learning framework for the firms that are tackling with CSR issues. Hence, we qualitatively bridge between organizational learning models and social learning approaches in order to foster a more advanced framework which recommends the employment of specific learning methods and styles to deal with CSR challenges based on the features of the firm and its business contextual considerations.
\end{abstract}

JEL Classification: M10, M14

Keywords: Organizational Learning (OL), Corporate Social Responsibility (CSR), Civil Learning, Learning Organization, Organizational Behavior

\section{Introduction}

Interest in corporate social responsibility has been increasing in recent years. (Zadek, 2004; Porter, 1999, 2006, 2011; ISO 26000, 2010) On the other hand, organizational

\footnotetext{
${ }^{1}$ Bielefeld Graduate School of Economics and Management (BiGSEM), Universitätsstrasse 25, D33615, Bielefeld, Germany. e-mail: akashefi@wiwi.uni

${ }^{2}$ Management and Soft Technology Faculty, Malek-Ashtar University of Technology, Babai Highway, Tehran, Iran.

e-mail: sanjaghi@yahoo.com
}

Article Info: Received: January 25, 2013. Revised : February 14, 2013.

Published online : May 1, 2013 
learning literatures have a longer history and several researches have been conducted by scholars with different viewpoints in this regard. (Argyris \& Schon, 1978; Fiol \& Lyles, 1985; Huber, 1991; Garvin, 1993; Stata, 1996; Yeung, 1999; Zadek, 2004) One of the most important research questions is which organizational learning approach fits better for firms to cope with social responsibility challenges. Relevant studies have been published by several researchers in distinct fields, including learning organization, organizational learning, corporate social responsibility, sustainability, organizational behavior, change management and strategic management. Nevertheless there seems to be a gap in management literatures dealing with this specific but very important issue. In this essay, a new framework is developed to address the above question.

Intense competition, globalization, broad international trade, global accessibility of internet, all, lead to fast-changing behavior of consumers on which the survival of corporations depends. Hence, organizations must adapt themselves with this dynamic changing environment (internally and externally). The necessary condition for being adaptive is to learn, learning from previous experiences, success and failure, yours and others, from different regions and different industries. Stata (1996) believes that within fast-changing business environment, learning is the only sustainable competitive advantage for corporations. Kotter (2012) proposed eight accelerators for an organization to "Change Faster"! He mentions that the short life cycle of big opportunities needs to create a sense of urgency around it and accordingly he proposed an optimal organizational structure to reap the potential benefits.

Faster changing environment requires more adaptive organizations that should learn faster. Thus, corporations need more specific learning models that could increase the speed of organizational learning. The core OL and CSR literature provides only limited insight about learning approaches toward social evolution of organizations. In this paper, we develop an OL framework which is tailored for corporations in proactively dealing with social responsibility challenges. In fact, our framework incorporates the findings of Zadek (2004) with OL styles of Yeung (1999).

In the next section we review some related literatures and concepts in the field of OL and CSR, then section three deals with our new framework and its related discussion and finally part four concludes.

\section{Literature Review and Fundamental Concepts}

Two streams of literature are relevant to our study: the first deals with organizational learning as a process for being adaptive against business environmental changes, and second investigates corporate social responsibility issues as a new challenge that could bring about threat or opportunity for an organization. These streams are combined in our paper, for we believe that firms require more developed OL framework in tackling CSR issues.

\subsection{Organizational Learning}

\subsubsection{Definition}

Fiol and Lyles (1985) judge the organizational learning with its objective outcomes and define it as the process of improving actions through better knowledge and understanding. 
Stata (1989) believes that organizational learning occurs through shared insights, knowledge, and mental models ... [and] builds on past knowledge and experience-that is, on memory. Huber (1991) describes learning and organizational learning in this way: "An entity learns if, through its processing of information, the range of its potential behavior is changed... an organization learns if any of its units acquires knowledge that it recognizes as potentially useful to the organization." Garvin (1993) also consider OL as an organization that is skilled in creating, acquiring and transferring knowledge, and at modifying its behavior to reflect new knowledge and insights. Argyris (1999) implies that organizational learning is the process of detection and correction of errors. He believes that organization learns from accomplished plans or from the reasons and troubleshooting of unaccomplished plans.

\subsubsection{Organizational learning fundamentals}

Levels of Learning: Several scholars deal with the issue of the level of learning and believe that learning take places in three different levels: Individual, group (or team) and organization. Probst and Buechel (1996) imply that organizational learning is both quantitatively and qualitatively distinct from the sum of the learning processes of individuals. Fiol and Lyles (1985) explain the capacity for organization level learning: "Organizations, unlike individuals, develop and maintain learning systems that not only influence their immediate members, but are then transmitted to others by way of organization histories and norms... Organizations do not have brains but they have cognitive systems and memories". All of these studies have one point in common that is organizational learning is more than the sum of the individual learning of each member. Indeed both, individual and group learning are the necessary (but not sufficient) conditions of organizational learning. The key aspect of organizational learning is the interaction that occurs among individuals and teams.

Another viewpoint toward levels of learning comes from the work by Fiol and Lyles (1985), and Yeung et al. (1999). They distinguished between lower levels of learning (superficial learning) -which is reactive learning that occurs within a given organizational structure and set of rules- and higher levels of learning (substantial learning) -which is proactive learning that try to adjust the overall rules and norms rather than specific activities and behavior (Yeung et al., 1999). The following table - which comes from Yeung et al. (1999) and Fiol and Lyles (1985) - illustrates the characteristics of these two levels of learning.

Learning Process: Yeung et al. (1999) considered four steps for organizational learning process as follows:

1) Discovery: finding a gap between expectation and actual results which show the need of new knowledge. (idea generation)

2) Invention: performance gaps' analysis and solution development. (idea generation)

3) Implementation: designed solution is implemented. (idea generalization)

4) Diffusion: individual learning of people is integrated to organizational learning and widely available through the firm. (idea generalization) 
Table 1: Lower level learning vs. higher level learning (Fiol \&Lyles, 1985; Yeung et al., 1999)

\begin{tabular}{|c|c|c|}
\hline & Superficial (Lower Level) & Substantial (Higher Level) \\
\hline Definitions & $\begin{array}{l}\text { First order learning } \\
\text { Single-loop learning } \\
\text { Gaining knowledge } \\
\text { Reactive learning }\end{array}$ & $\begin{array}{l}\text { Second order learning } \\
\text { Double-loop learning } \\
\text { Understanding rationale and } \\
\text { process behind knowledge } \\
\text { Proactive learning }\end{array}$ \\
\hline Characteristics & $\begin{array}{l}\text { Occurs through repetition } \\
\text { Routine } \\
\text { Control over immediate task, } \\
\text { rules \& structures }\end{array}$ & $\begin{array}{l}\text { Occurs through use of heuristics } \\
\text { and insights } \\
\text { Non-routine } \\
\text { Development of differentiated } \\
\text { structures, rules, etc. to deal with } \\
\text { lack of control }\end{array}$ \\
\hline Consequences & Behavioral outcomes & Cognitive outcomes \\
\hline Examples & $\begin{array}{l}\text { Institutionalizes formal rules } \\
\text { Adjustments in management } \\
\text { systems } \\
\text { Problem-solving skills }\end{array}$ & $\begin{array}{l}\text { New missions and statements of } \\
\text { strategic intent } \\
\text { Agenda setting systems } \\
\text { Problem-defining skills }\end{array}$ \\
\hline
\end{tabular}

Sources of Learning: Organizational learning requires knowledge acquisition, and acquiring knowledge thus requires that the information is available and that the firm actively searches for this information (Grant 1996). Javernick-Will (2009) defines knowledge acquisition as the firm's ability to acquire externally generated knowledge that is critical to their operations. She believes that learning occurs through two distinct sources: direct experience, or experiential knowledge. Yeung et al. (1999) mentioned direct experience and experience of others as the two sources of OL and elaborated the features of these two sources of learning. They believe that some contextual characteristics -in which an organization operates- including speed of environmental change, competitive strategy, slack resources, current success of organization, and ambiguity of technology affect the choice of learning method by an organization (industry-specific features). Table 2, which has been provided by Yeung et al. (1999), proposes the choice of learning sources considering some contextual characteristics.

Purposes of Learning: Many scholars imply that organizational learning should develop the performance, create competitive advantage and strategic capability in the world that change has become a norm rather than an exception (Fiol \& Lyles, 1985; Stata, 1989). Hamel and Prahalad (1994) mention that just being a learning organization is not sufficient. They believe that the learning process should lead to managerial competences which let the firm to better serve the customers' requirements. Yeung et al. (1999) explained two basic purposes of organizational learning: to explore new turf or exploit existing opportunities. To explore new turf, firms employ differentiation and technological leadership strategies while to exploit existing opportunities, they implement cost leadership strategy. 
Table 2: Contextual considerations in the choice of learning methods (Yeung et al. 1999)

\begin{tabular}{|l|l|l|}
\hline Contextual Characteristics & $\begin{array}{l}\text { Learning from Direct } \\
\text { Experience }\end{array}$ & $\begin{array}{l}\text { Learning from Experience } \\
\text { of Others }\end{array}$ \\
\hline $\begin{array}{l}\text { Speed of environmental } \\
\text { change }\end{array}$ & Changes rapidly & $\begin{array}{l}\text { Does not change too } \\
\text { rapidly }\end{array}$ \\
\hline Competitive strategy & $\begin{array}{l}\text { Product innovation and } \\
\text { differentiation }\end{array}$ & Cost leadership \\
\hline Slack resources & More abundant & More limited \\
\hline $\begin{array}{l}\text { Current success of } \\
\text { organization }\end{array}$ & Organization is successful & $\begin{array}{l}\text { Organization's } \\
\text { performance is not } \\
\text { satisfactory }\end{array}$ \\
\hline Ambiguity of technology & Less ambiguous & Ambiguous \\
\hline
\end{tabular}

\subsubsection{Organizational learning stages}

Yeung and Ulrich (1999) imply three stages to reach organizational learning capability: 1. the generation of ideas; 2 . the generalization of these ideas, and 3. the identification of learning disabilities, that is, barriers to generation and generalization.

Garvin (1993) believes that organizational learning is a process of passing three stages: cognitive, behavioral changes and performance improvement. cognitive where members are exposed to new ideas or knowledge; behavioral changes where members actually alter their behavior based on new learning; and finally, performance improvement where behavioral changes actual lead to positive business results in safety, quality, market share, and profitability. Cognitive and behavioral stages precede performance improvement. We discuss more on these three stages in the next section while proposing our own framework.

\subsubsection{Organizational learning styles}

Yeung et al. (1999), based on empirical studies of several leading corporations, determined four distinct styles of organizational learning: experimentation, competency acquisition, benchmarking, and continuous improvement.

1) Experimentation: learn by trying many new ideas and by accepting the experimentation of new products and processes. SONY, 3M and HP are three examples of organizations using this style.

2) Competency Acquisition: encouraging individuals and teams to acquire new competencies. This style relies on learning from experience of others and exploring new turfs. Motorola and GE are known for their competency acquisition style.

3) Benchmarking: scanning successful organizations' operation and attempting to adopt and adapt this knowledge for their own firm (learning from experience of others). Samsung and Xerox employ this style.

4) Continuous Improvement: learn by constantly improving on what has been done before moving on to new steps through a disciplined process. Toyota and Honda using continuous improvement style of learning.

By incorporation of the dimensions of "direct experience" vs. "experience of others" and "exploration of new turf" vs. "exploitation of existing opportunities", Yeung et al. (1999) empirically identifies a typology of four basic learning styles as indicated in figure 1. 


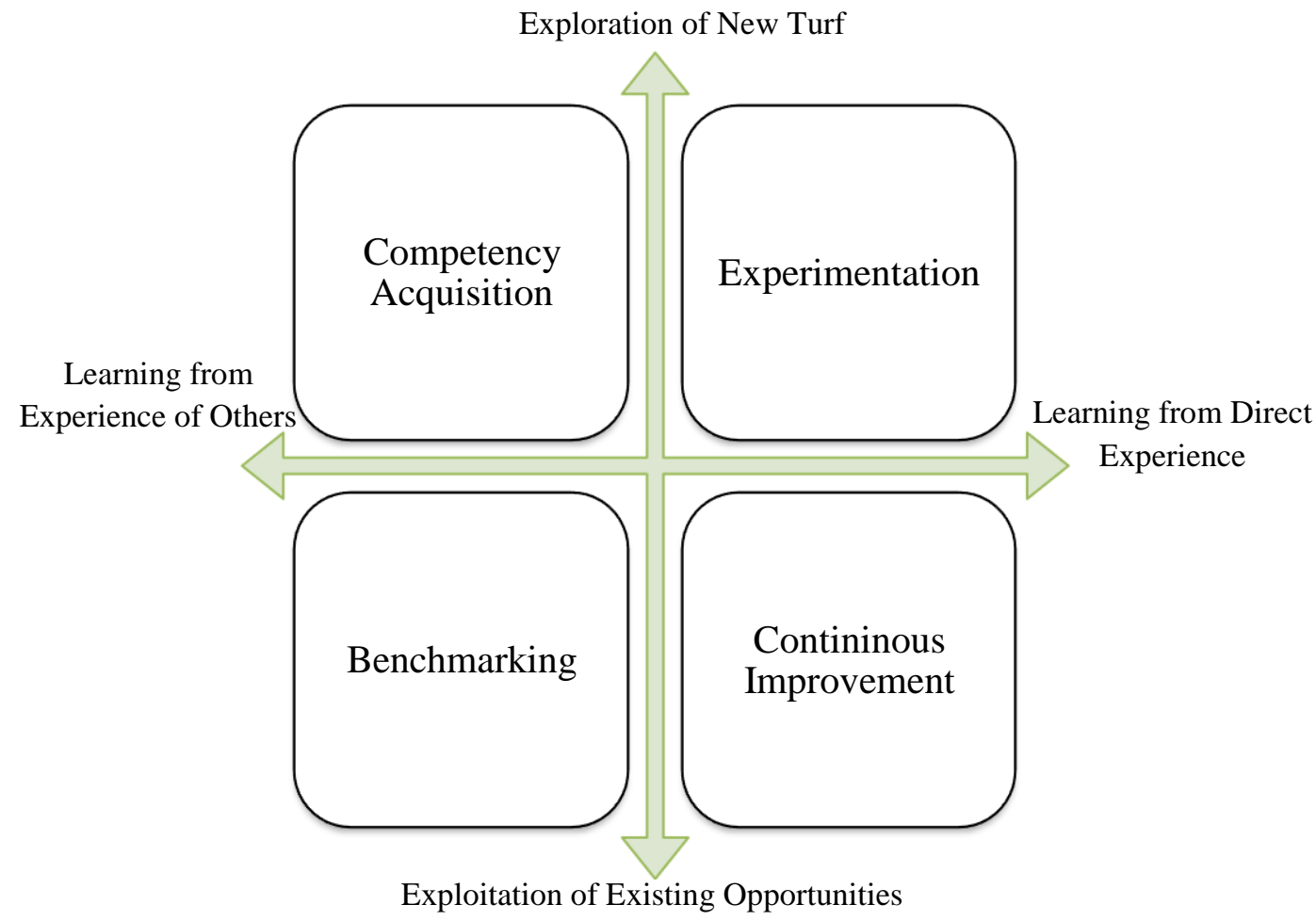

Figure 1: Typology of organizational learning (Yeung et al., 1999)

\subsection{Corporate Social Responsibility}

\subsubsection{Definition}

The concept of corporate social responsibility (CSR) has been evolved in recent years. Famous scholars as Michael Porter have contributed extensively to this area. Porter (2006, 2011) has changed the approach of looking to CSR from responsive-reactive approach to strategic-proactive one. He believes that CSR is not a cost or restriction and it should not be considered as charity, while it could be a source of opportunity, innovation and competitive advantage. Porter (2011) develop the new concept of creating shared value (CSV) as "Corporate policies and practices that enhance the competitiveness of the company while simultaneously advancing social and economic conditions in the communities in which it operates.". He mentions that firms should add the CSR issues in their profit function. Moreover International Standard Organization (ISO) recently (2010) has issued the first edition of Guidance on Social Responsibility, ISO 26000. They have introduced it so far as a voluntary standard for corporations which is still not obligatory, but the trend of social forces shows us some strong signals that it is very probable that ISO 26000 become a MUST very soon. Hence, firms should monitor this new trend seriously and learn how to tackle with this change. For this purpose, they need to equip themselves with proper organizational learning frameworks. 


\subsubsection{Civil Learning}

As business environment changes, it is imaginable that in more holistic viewpoint (Figure 2), social environment changes too, even though slower; so the society, for the sake of survival, should learn too. Paying attention to healthy and organic foods, recyclable packages, bio products, working conditions of labor are just some examples of social maturity. Protests against SHELL in 1995 and NIKE in 1990 are just two famous headlined cases of this kind. (Porter, 2006) These pressures from society, government, media, activists, NGOs and even recently published ISO 26000 documents have become a significant challenge for corporations. Society's expectation from corporations has changed and this change should be responded fast and effectively. Hence firms should adapt themselves with this new dilemma by entering a particular kind of learning. Zadek (2004) named it Civil Learning: "Moreover, just as organizations' views of an issue grow and mature, so does society's. Beyond getting their own houses in order, companies need to stay abreast of the public's evolving ideas about corporate roles and responsibilities. A company's journey through these two dimensions of learning-organizational and societal - invariably leads it to engage in what I call civil learning."

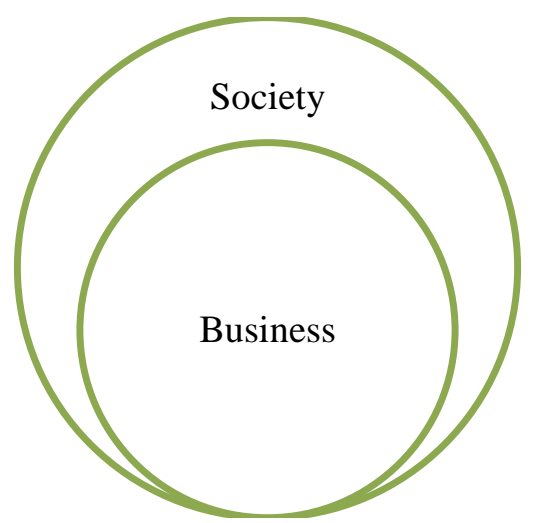

Figure 2: Business and Society

\subsubsection{CSR Learning stages}

Zadek (2004) implies that the path to good corporate citizenship navigate through five subsequent stages. It starts from completely denying the existence of problem (Defensive stage) to adopt the minimum level of responsibility as a cost of doing business (Compliant stage). Then firms learn to integrate social issues into their daily operations (Managerial stage). Through the evolution, they realize that CSR could be a source of strategic opportunity and competitive advantage; hence, they incorporate social issue into their strategies (Strategic stage). Finally they learn to signal other corporations in the industry to actively participate in these social issues to benefit more through collective actions (Civil stage). He believes that "while every organization learns in unique ways, most pass through five discernible stages in how they handle corporate responsibility". Table 3 explains these five stages with more details.

We contribute to the extent literature on OL and CSR by simultaneously considering them and proposing fitted OL styles toward social evolution of organizations and attempting to bridge the gap between these two streams of literature. In fact our framework is built on the theory of Simon Zadek (2004) and deals with this issue that when firms encounter 
corporate social responsibility challenges, which organizational leaning styles, based on Yeung (1999), needed to pass through the social evolution stages. Our framework is going to qualitatively combine the Zadek's stages with some models of organizational learning. Then we suggest the appropriate OL style to pass these five stages based on industry-specific features of firms.

Table 3: CSR learning stages (Zadek, 2004)

\begin{tabular}{|c|c|c|}
\hline Stage & What Companies Do & Why Companies Do It \\
\hline Defensive & $\begin{array}{l}\text { Deny existence of problematic } \\
\text { practices, or responsibility for } \\
\text { addressing them. }\end{array}$ & $\begin{array}{l}\text { To defend against attacks that } \\
\text { could affect short-term sales, } \\
\text { recruitment, productivity, and the } \\
\text { brand. }\end{array}$ \\
\hline Compliant & $\begin{array}{l}\text { Adopt a policy-based compliance } \\
\text { approach as a cost of doing } \\
\text { business. }\end{array}$ & $\begin{array}{l}\text { To mitigate the erosion of } \\
\text { economic value in the medium } \\
\text { term because of ongoing } \\
\text { reputation and litigation risks. }\end{array}$ \\
\hline Managerial & $\begin{array}{l}\text { Give managers responsibility for } \\
\text { the social issue and its solution, } \\
\text { and integrate responsible business } \\
\text { practices into daily operations. }\end{array}$ & $\begin{array}{l}\text { To mitigate medium-term erosion } \\
\text { of economic value and achieve } \\
\text { longer term gains. }\end{array}$ \\
\hline Strategic & $\begin{array}{l}\text { Integrate the societal issue into } \\
\text { their core business strategies. }\end{array}$ & $\begin{array}{l}\text { To enhance economic value in the } \\
\text { long run and gain first mover } \\
\text { advantage over rivals. }\end{array}$ \\
\hline Civil & $\begin{array}{l}\text { Promote broad industry } \\
\text { participation in corporate } \\
\text { responsibility. }\end{array}$ & $\begin{array}{l}\text { To enhance long-term economic } \\
\text { value and realize gains through } \\
\text { collective action. }\end{array}$ \\
\hline
\end{tabular}

\section{Framework}

In this section we draw our framework on the findings of Zadek's CSR learning stages and Yeung's OL methods and styles. Our aim is to bridge two relevant, but not integrated, concepts of organizational learning and CSR learning. Although CSR learning is a particular subset of OL, we strongly believe that it deserves a distinct consideration. Our framework clarifies the significant position of CSR learning in the broader context of organizational learning and proposes a number of appropriate learning methods toward 
social evolution of corporations. First, we consolidate CSR learning stages as established by Zadek (2004) with two other broader concepts of OL containing levels of learning (Fiol and Lyles, 1985), and OL stages (Garvin, 1993). This comparative analysis sheds more light on the characteristics of each of CSR learning stages as a subset of OL. Second, we propose our framework which suggests the employment of appropriate learning methods to be relevant for each stage of CSR learning.

Figure 3 graphically compares the five CSR learning stages of Zadek (2004) with two learning levels of Fiol and Lyles (1985). It implies that when firms encounter CSR challenges, their learning levels start from superficial to substantial ones. Based on the concepts of table 1 and 3, firms deny the CSR problem at defensive stage and try to reject their social responsibility. This is a strong sign of reactive learning approach for a firm that is just gaining knowledge. In this stage and the second stage (compliant), firms modify their actions according to the differences between expected and realized outcomes (single-loop learning of Argyris and Schoen, 1978). Indeed, firms are trying to solve the CSR problem in order to avoid short and medium term loss. We believe that managerial stage (third stage) reflects both superficial and substantial levels of learning as there are some signs of moving from the surface to the depth. In fact managerial stage can be considered as a transition stage from superficial to substantial level. This fact that a firm asks its managers to deal with CSR problems and integrate it into its business operations, illustrate the beginning of double-loop and proactive learning. As firms move over the curve, this levels of OL deepens such that in the strategic stage (fourth stage), firms integrate social issues into their core business strategies. Porter (2006) called it strategic CSR versus responsive CSR. In this stage, firms approach the CSR issues as a source of innovation, opportunity and competitive advantage (Porter, 2006, 2011) and by defining new problems, try to revise their strategic intents. Indeed, corporations revise their values, assumptions, policies, and strategies to reach more benefits compare to their rivals (double-loop learning of Argyris and Schoen, 1978). Moreover, it can be seen that behavioral reactions of first and second stages develop to cognitive consequences of upper stages. Finally, at the last stage (civil stage), firms signal other players in their industry to participate in order to reduce their own costs and gain more from collective CSR activities.

Superficial

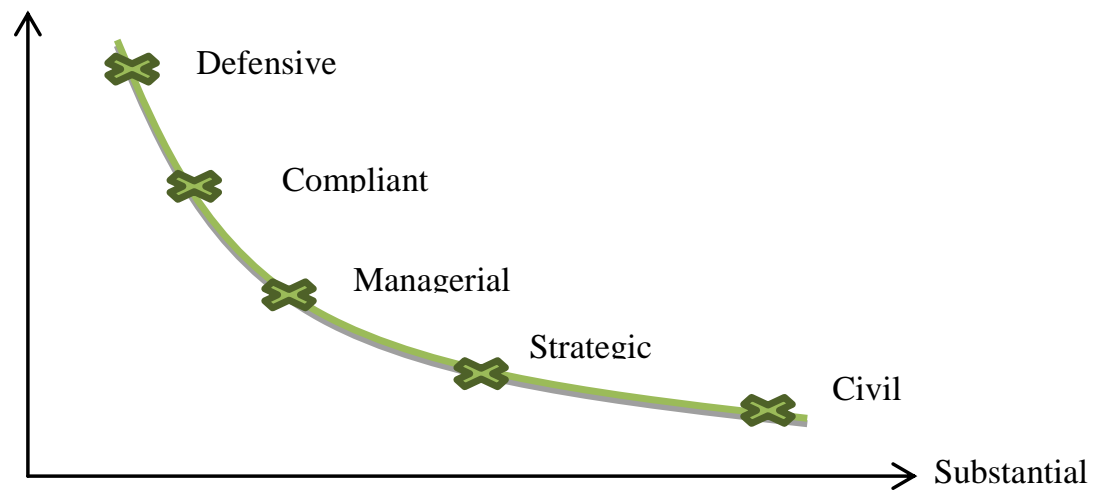

Figure 3: Levels of Learning (Fiol \& Lyles, 1985) vs. CSR Learning Stages (Zadek, 2004) 
Table 4 compares five stages of CSR learning of Zadek (2004) with organizational learning stages of Garvin (1993). Garvin (1993), as mentioned in subsection 2.1.3, approached OL as a process of passing three different stages: cognitive, behavioral, and performance improvement such that each stage precedes the next one. Now consider firms that encounter CSR challenges: at defensive stage, firms are exposed to a new knowledge that is social responsibility issues. Hence, idea generation occurs and as firms still are not organized in facing the problem, they defend against attacks from society, Medias, government, and NGOs. Problem-solving by denying the dilemma and reactive behavior are the characteristics of this defensive stage. Indeed in this stage, firms are involved more, but not optimal, in cognitive phase of learning which implies less behavioral changes and lack of performance improvement. Under more pressure from external players like Medias and government, firms in compliant stage adopt some policy-based approach in order to keep their business reputation and decrease the risks. These activities imply deeper cognitive learning plus some behavioral changes, but still without clear performance improvement. Continuity of CSR challenges and threats of long-term loss, enforce the managers to integrate the CSR issues into their routine operations and look at it as a problem that should be managed and solved (managerial stage). Indeed in this stage, firms have some performance improvement which caused by more developed level of preceding cognitive and behavioral learning. In the next two stages, strategic and civil, firms modify their long-term strategies considering CSR issues. They try to reap the potential benefits of strategic CSR. For this end, they signal other funders (Porter, 1999) to cooperate in collective social activities in order to reduce their costs and reach more gains. Clearly, at the civil stage, they have obtained optimal amounts of OL stages including cognitive, behavioral and performance improvement.

Table 4: CSR learning stages (Zadek, 2004) vs. OL stages (Garvin, 1993)

\begin{tabular}{|c|l|c|c|c|}
\hline \multicolumn{2}{|c|}{} & \multicolumn{3}{c|}{ Garvin's OL Stages (1993) } \\
\hline \multirow{2}{*}{} & Learning Stages & Cognitive & Behavioral & $\begin{array}{c}\text { Performance } \\
\text { Improvement }\end{array}$ \\
\cline { 2 - 5 } & Defensive & $* * *$ & $*$ & $*$ \\
\cline { 2 - 5 } $\begin{array}{c}\text { Zadek's } \\
\text { CSR } \\
\text { Learning } \\
\begin{array}{c}\text { Stages } \\
(2004)\end{array}\end{array}$ & Compliant & $* * * *$ & $* *$ & $*$ \\
\cline { 2 - 5 } & Managerial & $* * * *$ & $* * *$ & $* *$ \\
\cline { 2 - 5 } & Strategic & $* * * * *$ & $* * * *$ & $* * * *$ \\
\cline { 2 - 5 } & Civil & $* * * * *$ & $* * * *$ & $* * * *$ \\
\hline
\end{tabular}

Note: The star signs (*) imply the density of relationship between elements of the table, that are very weak $(*)$, weak $(* *)$, average $(* * *)$, strong $(* * * *)$, and very strong $(* * * * *)$.

Hereafter, based on table 2, table 3, and figure 1, we are going to present our framework. As explicitly mentioned in introduction, this framework intends to answer the following 
research question: which organizational learning approaches fits better for firms to cope with CSR challenges? Table 5 depicts the framework.

As we discussed in subsection 2.1.2, organizational learning requires knowledge acquisition (Grant, 1996) and based on Yeung et al. (1999), there are two distinct sources of learning: direct experience and experience of others. According to table 2, when business environment changes rapidly, when firms are successful innovative entities and have large amount of resources, and also when their employed technology is not very complex, they can be better off by the choice of "direct experience" as their learning method. Now consider firms which are labeled with these contextual considerations and these firms face CSR challenges. In passing the five CSR learning stages, our framework suggests which OL styles (experimentation or continuous improvement) fits better for these firms that have chosen direct experience (based on above mentioned contextual considerations).

Table 5: A New Framework

\begin{tabular}{|l|c|c|c|c|}
\hline \multirow{2}{*}{} & \multicolumn{4}{|c|}{ Choices of Learning Methods (Yeung et al., 1999) } \\
\hline $\begin{array}{c}\text { CSR Learning } \\
\text { Stages (Zadek, } \\
\text { 2004) }\end{array}$ & \multicolumn{3}{|c|}{ Direct Experience } & \multicolumn{2}{c|}{ Experience of Others } \\
\cline { 2 - 5 } & Experimentation & $\begin{array}{c}\text { Continuous } \\
\text { Improvement }\end{array}$ & $\begin{array}{c}\text { Competency } \\
\text { Acquisition }\end{array}$ & Benchmarking \\
\hline Defensive & $\checkmark$ & & $\checkmark$ & $\checkmark$ \\
\hline Compliant & & $\checkmark$ & $\checkmark$ & $\checkmark$ \\
\hline Managerial & $\checkmark$ & $\checkmark$ & & \\
\hline Strategic & & $\checkmark$ & \multicolumn{2}{c}{ Excellence } \\
\hline Civil & & & & $\checkmark$ \\
\hline
\end{tabular}

For passing the defensive stage and get to compliant, experimentation style of learning is proposed by our framework. In defensive stage, as firms newly encounter CSR challenges, they are still gaining knowledge and generating new ideas. Indeed based on figure 3, they are experiencing superficial level of OL. As still CSR challenges are not deepened in this stage, firms have the time and opportunity to pass it with lower costs by their own experimentation. It implies they can try new ideas and adopt some policy-based approach in order to save their brand reputation and mitigate the harms (Note that we are dealing with organizations that act within above mentioned contextual consideration and choose direct experience).

To reach the managerial stage, we suggest the employment of continuous improvement style. In managerial stage, managers are responsible for problem-solving; they are obliged to integrate CSR issues into normal course of business. This disciplined organizational process needs constant development of the norms, policies, and some structures of firms which characterize the usage of continuous improvement style. In fact, coordination 
between all departments of organizations and smooth movement toward new agendas, justify this learning style.

Experimentation is proposed for passing the managerial to strategic stage. Looking at CSR as a source of opportunity instead of cost and charity-deed (Strategic CSR) actually requires the generation of new strategic ideas to add social some dimensions to value propositions of corporations. This strategic planning process requires the experimentation of state of the art tools and technologies. Gaining first mover advantage over rivals as mentioned by Zadek (2004), table 3, needs experimentation and investment in R\&D.

Finally, we propose continuous improvement style to reach the civil learning stage. This stage contains a kind of organizational excellence in CSR learning as several corporations in an industry enter collective CSR activities which result in more effective outcomes for businesses and society. Promotion of extensive industry participation requires signaling other firms of the industry to engage in CSR activities. This disciplined process takes time and needs systematic efforts which should be constantly developed to gain optimal outcomes.

Now, based on table 2, consider the inverse contextual considerations compare to previous discussion. It implies that when speed of business environment does not change so fast, when firms choose cost leadership as their competitive strategy and have limited resources, and also when the performance of corporations is not enough satisfactory, and their employed technology is ambiguous, they will be better off by the choice of "experience of others" as their learning method. Now consider firms which are recognized with these contextual considerations and these firms encounter CSR challenges. For moving through the five CSR learning stages, our framework proposes which OL styles (benchmarking or competency acquisition) fits better for these firms that have chosen the usage of experiences of others.

Based on above mentioned contextual consideration, our framework proposes benchmarking style for passing the defensive stage. As our firms are assumed not to be very successful, and operate in a business environment with moderate speed of changes, it will be better to choose benchmarking to see what the other firms have done to save their reputation and short term profits. Compared to competency acquisition, benchmarking also can get firms to compliant stage more rapidly which is a major consideration in keeping their business reputation and risk reduction. For instance, firms can learn by benchmarking from the late and mistaken reactions of NIKE during 1990s which led to a huge boycott campaign against its production (Zadek, 2004; Porter, 2006).

To reach the managerial stage, competency acquisition is proposed by the framework. Managerial stage requires capable managers who have problem solving skills and the ability to integrate social responsibility issues into normal operations of their firms. For getting these capabilities, management teams of an organization should acquire some essential competencies. This style of learning takes more time than benchmarking and requires a systematic planning in firm level.

Furthermore, since at the strategic stage, firms should add some social dimensions to their value proposition (Porter, 2006) to approach CSR strategically, and this process requires more managerial capabilities, we propose competency acquisition as an appropriate learning style. Revision of former strategies and integrate social issues into core business strategies as stated in table 3, need deep insight and knowledge of the business environment as well as the society in which firms operate. Indeed strategic stage should be handled by top managers of firms provided the existence of relevant organizational culture that supports social attitude of workers. Benchmarking also can be employed to 
reach the strategic stage, but as firms differ industry to industry and even unit to unit, hence, it might be not so effective to follow the others experience.

Finally we propose benchmarking to get to the civil learning stage as business excellence in this regard. We believe that unsatisfactory performance of firms beside the moderate speed of environmental changes and limited resources justify the employment of benchmarking style. Signaling other funders (Porter, 1999) and encourage the extensive industry participation in CSR issues, requires a leadership position among other rivals and partners which is very hard to acquire for unsuccessful firms with limited resources.

\section{Conclusion}

Firms in confrontation with social responsibility challenges pass through five distinct learning stages which are first introduced by Zadek (2004). Zadek in his valuable paper, based on studying the behavior of several leading companies, described the characteristics of these five stages. Indeed he has not dealt with the issue that out of various organizational learning methods and styles, which one would be appropriate for each stage of social evolution of corporations. This essay tried to resolve this issue by proposing a new framework which explicitly suggests the employment of proper OL methods and styles relevant to specific business contextual considerations. In fact we have shown that firms, in facing CSR challenges, should first determine their positions based on their contextual considerations and accordingly apply suitable learning methods and styles. This process prevents wasting of organizational resources and reduces the excessive costs of handling CSR challenges. Moreover, as a by-product of our new framework, we also incorporated five CSR learning stages of Zadek (2004) with levels of learning (superficial and substantial) of Fiol and Lyles (1985) and with OL stages (cognitive, behavioral, and performance improvement) of Garvin (1993). Our intention was to shed more light on the connection between typical concepts of OL and the newbrand concept of civil learning.

Our framework has some limitations. Firms usually operate in uncertain, fast-changing business environment with possibility of facing unexpected issues such as economic recession, and establishment of new rules and regulations of the host countries. These unexpected consequences could eliminate the possibility of employing some proposed learning methods and styles. A fruitful avenue for further research here would be the modification and development of our framework by doing empirical studies.

\section{References}

[1] C. Argyris and D.A. Schoen, Organizational learning: A theory of action perspective, San Francisco: Jossey-Bass, CA, 1978.

[2] C. Argyris, On Organizational Learning (2nd Edition), Blackwell Business Publishers Inc., Oxford, 1999.

[3] C.M. Fiol and M.A. Lyles, Organizational learning, Academy of Management Review, 10(4), (1985), 803-813.

[4] D. Garvin, Building a learning organization, Harvard Business Review, 7(4), (1993), 78-91. 
[5] R. Grant, Toward a Knowledge-Based Theory of the Firm, Strategic Management Journal, 17, (1996), 109- 122.

[6] G. Hamel and C.K. Prahalad, Competing for the Future, Harvard Business School Press, Boston, MA, 1994.

[7] G.P. Huber, Organizational learning: The contributing processes and literatures, Organizational Science, 2(1), (1991), 88- 115.

[8] ISO, Guidance on Social Responsibility, ISO 26000:2010(E), Geneva: ISO, 2010.

[9] A. Javernick-Will, Organizational Learning during Internationalization: Acquiring Local Institutional Knowledge, Working Paper \#46, Collaboratory for Research on Global Projects (CRGP), Stanford, CA, 2009.

[10] D.H. Kim, The link between individual and organizational learning, Sloan Management Review, Fall Issue, (1993), 37- 50.

[11] J. Kotter, Accelerate, Harvard Business Review, 90(11), (2012), 44- 58.

[12] M.E. Porter and M.R. Kramer, Philanthropy's New Agenda: Creating Value, Harvard Business Review, 77(6), (1999), 121- 130.

[13] M.E. Porter and M.R. Kramer, Strategy and Society: The Link between Competitive Advantage and Corporate Social Responsibility, Harvard Business Review, 84(12), (2006), 78- 92.

[14] M.E. Porter and M.R. Kramer, Creating Shared Value, Harvard Business Review, 89(1), (2011), 62- 77.

[15] G. Probst and B. Buechel, Organizational Learning: The competitive advantage of the future, London: Prentice-Hall, 1996.

[16] B.B. Scott, Organizational Learning: A Literature Review, Discussion Paper \#201102, IRC Research Program, Queen's University, 2011.

[17] A. Small and P. Irvine, Toward a Framework for Organizational Learning, The Learning Organization, 13(3), (2006), 276- 299.

[18] R. Stata, Organizational learning: the key to management innovation, Sloan Management Review, 30(Spring Issue), (1989), 63- 74.

[19] R. Stata, Organizational Learning: The Key to Management Innovation, Sloan Management Review, 30(3), (1996), 63- 74.

[20] A. Yeung, D. Ulrich, S. Nason and M. Von Glinow, Organizational Learning Capability, New York, NY: Oxford University Press, 1999.

[21] S. Zadek, The Path to Corporate Responsibility, Harvard Business Review, 82(12), (2004), 125- 132. 